\title{
Prevalência de trematódeos do gênero Clinostomum em Jundiás (Rhamdia quelen) e desenvolvimento de um método de diagnóstico através de PCR
}

\author{
Prevalence of trematodes of the genus Clinostomum in Jundiás (Rhamdia quelen) and development \\ of a diagnostic method by PCR \\ Prevalencia de trematodos del género Clinostomum en Jundiás (Rhamdia quelen) y desarrollo de un \\ método diagnóstico mediante PCR
}

\section{Resumo}

Clinostomum complanatum Rudolphi, 1814 é um trematódeo digenético que infecta moluscos, diversas espécies de peixes de água doce e pássaros piscívoros. Em seu ciclo de vida, o C. complanatum possui como segundo hospedeiro intermediário alguns peixes de água doce, dentre os quais o Jundiá (Rhamdia quelen). Desse modo, o objetivo do presente estudo foi avaliar a prevalência de infecções por Clinostomum em Jundiás capturados na região estuária de Pelotas/RS e padronizar a Reação em Cadeia da Polimerase (PCR) para diagnóstico da presença de metacercárias em amostras de tecidos de peixes capturados neste estuário. Para a realização do estudo transversal e padronização da PCR, utilizou-se 174 amostras de Jundiás (Rhamdia quelen), capturados por pescadores amadores em 5 diferentes pontos em locais próximos à Laguna dos Patos, Lagoa Mirim ou o Canal São Gonçalo. A prevalência de parasitismo por Clinostomum spp. com diagnóstico através de chaves parasitológicas foi de $36,21 \%$, com variações da prevalência de acordo com os pontos relatados de captura dos espécimes de Jundiá, sendo confirmado a partir da PCR padronizada. Conclui-se que a prevalência é alta nos jundiás analisados e a PCR pode ser uma ferramenta auxiliar no diagnóstico desse parasita elevando não só a sensibilidade, mas também a rapidez do teste. Tais fatores serão de grande importância para futuros estudos epidemiológicos, assim como para saúde pública, visto que o consumo de peixes de água doce, típico da culinária oriental, encontra-se em expansão no Rio Grande do Sul e no Brasil.

Palavras-chave: Parasitismo; Saúde pública; Diagnóstico molecular; Peixes.

\section{Abstract}

Clinostomum complanatum Rudolphi, 1814 is a digenetic trematode that infects mollusks, several species of freshwater fish and piscivorous birds. In its life cycle, C. complanatum has as its second intermediate host some 
freshwater fish, among which Jundiá (Rhamdia quelen). Thus, the aim of the present study was to evaluate the prevalence of Clinostomum infections in Jundiás captured in the estuary region of Pelotas/RS and to standardize a Polymerase Chain Reaction (PCR) to diagnose the presence of metacercariae in tissue samples from fish captured in this estuary. In the cross-sectional study and the standardization of PCR, 174 samples of Jundiás (Rhamdia quelen), captured by amateur fishermen at 5 different points in locations close to Laguna dos Patos, Lagoa Mirim or the São Gonçalo Channel were used. The prevalence of parasitism by Clinostomum spp. with diagnosis through parasitological keys was $36.21 \%$, with variations in prevalence according to the reported capture points of specimens from Jundiá, being confirmed by standardized PCR. It is concluded that the prevalence is high in the analyzed silver catfish and PCR can be an auxiliary tool in the diagnosis of this parasite, increasing not only the sensitivity, but also the speed of the test. Such factors will be of great importance for future epidemiological studies, as well as for public health, since the consumption of freshwater fish, typical of oriental cuisine, is expanding in Rio Grande do Sul and Brazil.

Keywords: Parasitism; Public health; Molecular diagnosis; Fish.

\section{Resumen}

Clinostomum complanatum Rudolphi, 1814 es un trematodo digenetic que infecta a los moluscos, varias especies de peces de agua dulce y aves piscívoras. En su ciclo de vida, $C$. complanatum tiene como segundo hospedador intermedio algunos peces de agua dulce, entre los que se encuentran Jundiá (Rhamdia quelen). Así, el objetivo del presente estudio fue evaluar la prevalencia de infecciones por Clinostomum en Jundiás capturadas en la región del estuario de Pelotas/RS y estandarizar la Reacción en Cadena de la Polimerasa (PCR) para diagnosticar la presencia de metacercarias en muestras de tejido de peces capturados en este estuario. Para realizar el estudio transversal y estandarización de la PCR, se utilizaron 174 muestras de Jundiás (Rhamdia quelen), capturadas por pescadores aficionados en 5 puntos diferentes en localidades cercanas a Laguna dos Patos, Lagoa Mirim o Canal São Gonçalo. La prevalencia de parasitismo por Clinostomum spp. con diagnóstico por claves parasitológicas fue de 36,21\%, con variaciones en la prevalencia según los puntos de captura reportados de los especímenes de Jundiá, siendo confirmada por PCR estandarizada. Se concluye que la prevalencia es alta en el bagre plateado analizado y la PCR puede ser una herramienta auxiliar en el diagnóstico de este parásito, aumentando no solo la sensibilidad, sino también la rapidez de la prueba. Tales factores serán de gran importancia para futuros estudios epidemiológicos, así como para la salud pública, ya que el consumo de pescado de agua dulce, típico de la cocina oriental, se está expandiendo en Rio Grande do Sul y Brasil.

Palabras clave: Parasitismo; Salud pública; Diagnóstico molecular; Peces.

\section{Introdução}

Clinostomum complanatum Rudolphi, 1814 é um trematódeo digenético que infecta moluscos, diversas espécies de peixes de água doce e pássaros piscívoros (Lo et al., 1981). Tal parasita possui uma distribuição global e tem sido reportado no Brasil, inclusive em um peixe (Rhamdia quelen) de água doce importante economicamente e popularmente conhecido como "Jundiá" (Vianna et al., 2005; Silva et al., 2008; Dias et al., 2016).

$R$. quelen reside em várzeas, onde ocorrem periódicas secas e inundações. Essas particularidades do ambiente fizeram com que essa espécie se adaptasse a locais de condições extremamente dinâmicas (Dias et al., 2006). Dessa forma, $R$. quelen tem apresentado resultados satisfatórios na piscicultura, gerando relevante interesse no cultivo da espécie.

Em seu ciclo de vida, o C. complanatum, possui como segundo hospedeiro intermediário, alguns peixes de água doce, dentre os quais o Jundiá está inserido. Quando a metacercária desse parasita infecta seu hospedeiro, ela pode se alocar em diversos órgãos e tecidos do mesmo, inclusive os músculos, barbatanas e outras cavidades corporais resultando em alterações comportamentais e patológicas, como a Doença dos Pontos Amarelos (Thatcher, 1981).

Os cistos formados por essa metacercária são majoritariamente amarelos e, portanto, quando fixados em músculos geram um aspecto desagradável na carne do peixe que, por sua vez, é descartado durante a inspeção (Eiras et al., 1999; Miller et al., 2004). Além disso, quando existem grandes cistos anexados às barbatanas, dificulta a locomoção do peixe e, consequentemente, sua busca por alimento (Pavanelli et al., 1998). Todos esses fatores direcionam-se à notáveis consequências para o animal, refletindo na sua saúde e em perdas econômicas.

Adicionalmente, o C. complanatum também possui potencial zoonótico e alguns autores já relataram casos de faringite ou laringite em humanos que consumiram peixes de água doce crus, os quais estavam infectados por metacercárias do 
parasito (Lee et al., 2017; Park et al., 2009; Hara et al., 2014). Quando ingerida, a metacercária atinge o estômago e desencista, após isso, ela migra para a garganta e fixa-se causando uma reação inflamatória no local (Song et al., 2018).

Devido às perdas econômicas, assim como o potencial zoonótico desse trematódeo, a busca pela eficácia dos ensaios tornou-se alvo nos recentes anos. Técnicas moleculares, especialmente a reação em cadeia da polimerase (PCR), tem sido alvos de estudo (Simsek., 2018). Desse modo, o objetivo do presente estudo foi avaliar a prevalência de infecções por Clinostomum em Jundiás capturados na região estuária da Laguna dos Patos e Canal São Gonçalo, na região de Pelotas (RS), e padronizar uma PCR para diagnóstico da presença de metacercárias de Clinostomum em amostras de tecidos de peixes capturados neste estuário.

\section{Metodologia}

Para a realização do estudo observacional transversal de natureza quantitativa (Pereira et al., 2018), utilizou-se amostras de Jundiás (Rhamdia quelen), capturados por pescadores amadores em 5 diferentes pontos em locais próximos à Laguna dos Patos, Lagoa Mirim ou o Canal São Gonçalo (Tabela 1). As amostras eram trazidas pelos pescadores, onde os espécimes eram quantificados, inspecionados visualmente, retiradas as nadadeiras e guelras e devolvida a carcaça dos peixes aos pescadores, para que as mesmas fossem utilizadas aos seus originais propósitos.

Tabela 1. Locais de captura de Jundiás (Rhamdia quelen) por pescadores amadores nas regiões entre a Laguna dos Patos e a Lagoa Mirim, no período de março a novembro de 2019.

\begin{tabular}{lll}
\hline Ponto de captura & Latitude & Longitude \\
\hline Ponto 1 - Lagoa do Fragata & $31^{\circ} 47^{\prime} 40.20 " \mathrm{~S}$ & $52^{\circ} 23^{\prime} 24.03^{\prime \prime} \mathrm{O}$ \\
Ponto 2 - Barragem Eclusa & $31^{\circ} 48^{\prime} 55.38^{\prime \prime} \mathrm{S}$ & $52^{\circ} 23^{\prime} 30.16^{\prime \prime} \mathrm{O}$ \\
Ponto 3 - Foz do Piratini & $31^{\circ} 58^{\prime} 39.46^{\prime \prime} \mathrm{S}$ & $52^{\circ} 25^{\prime} 16.38^{\prime \prime} \mathrm{O}$ \\
Ponto 4 - Lagoa Formosa & $32^{\circ} 04^{\prime} 28.35 " \mathrm{~S}$ & $52^{\circ} 31^{\prime} 22.93^{\prime \prime} \mathrm{O}$ \\
Ponto 5 - Santa Isabel & $32^{\circ} 07^{\prime} 09.84^{\prime \prime} \mathrm{S}$ & $52^{\circ} 36^{\prime} 04.38^{\prime \prime} \mathrm{O}$ \\
\hline
\end{tabular}

Fonte: Autores.

O período de recebimento das amostras foi de março a novembro de 2019, respeitando os períodos de defeso para a piracema, sem receber amostras de peixes capturados fora deste período. Os espécimes encaminhados eram imediatamente quantificados, visualmente inspecionados, guelras e nadadeiras eram retiradas e as carcaças devolvidas aos pescadores para que fossem direcionadas aos seus respectivos fins.

Após a análise visual, as amostras que continham lesões suspeitas foram encaminhadas para realização de exames histopatológicos no Laboratório Regional de Diagnóstico da Universidade Federal de Pelotas (LRD-Faculdade de Veterinária).

Os resultados foram confirmados utilizando chaves parasitológicas e exame microscópico direto das lesões (Figura 1). Posteriormente às análises, as amostras positivas para Clinostomum spp confirmadas por histopatologia foram encaminhadas para extração de DNA e formação de banco de DNA para uso como controle positivo. As amostras suspeitas foram submetidas também a extração de DNA para o uso na detecção por PCR.

A extração de DNA genômico foi realizada com o Kit "Blood/Tissue DNA Mini Kit da Mebep Bioscience (Ludwig Biotec)". O DNA extraído era validado através de eletroforese em Gel de Agarose 1,5\% e quantificação por espectrofotometria no aparelho Nanodrop ${ }^{\circledR}$. Após confirmada a extração do DNA, as amostras foram armazenadas em um ultrafreezer a $-78^{\circ} \mathrm{C}$. Para o desenho dos primers, as sequências de DNA utilizadas foram baseadas nas disponíveis no Genbank, acessadas através da sequência KM923964, referentes ao genoma completo do DNA mitocondrial do Clinostomum complanatum. 
Figura 1. Análise macroscópica e histopatológica realizada no laboratório, onde: (A) Rhamdia quelen parasitado, com presenças de metacercárias de Clinostomum spp. nas brânquias e músculos; (B) Rhamdia quelen com metacercárias de Clinostomum spp nas nadadeiras caudais; (C) e (D) Corte histológico em tamanhos diferentes de fragmento do músculo de jundiá (Rhamdia quelen) com cistos aderidos e com a presença de metacercárias progenéticas de Clinostomum spp. dentro dos cistos.

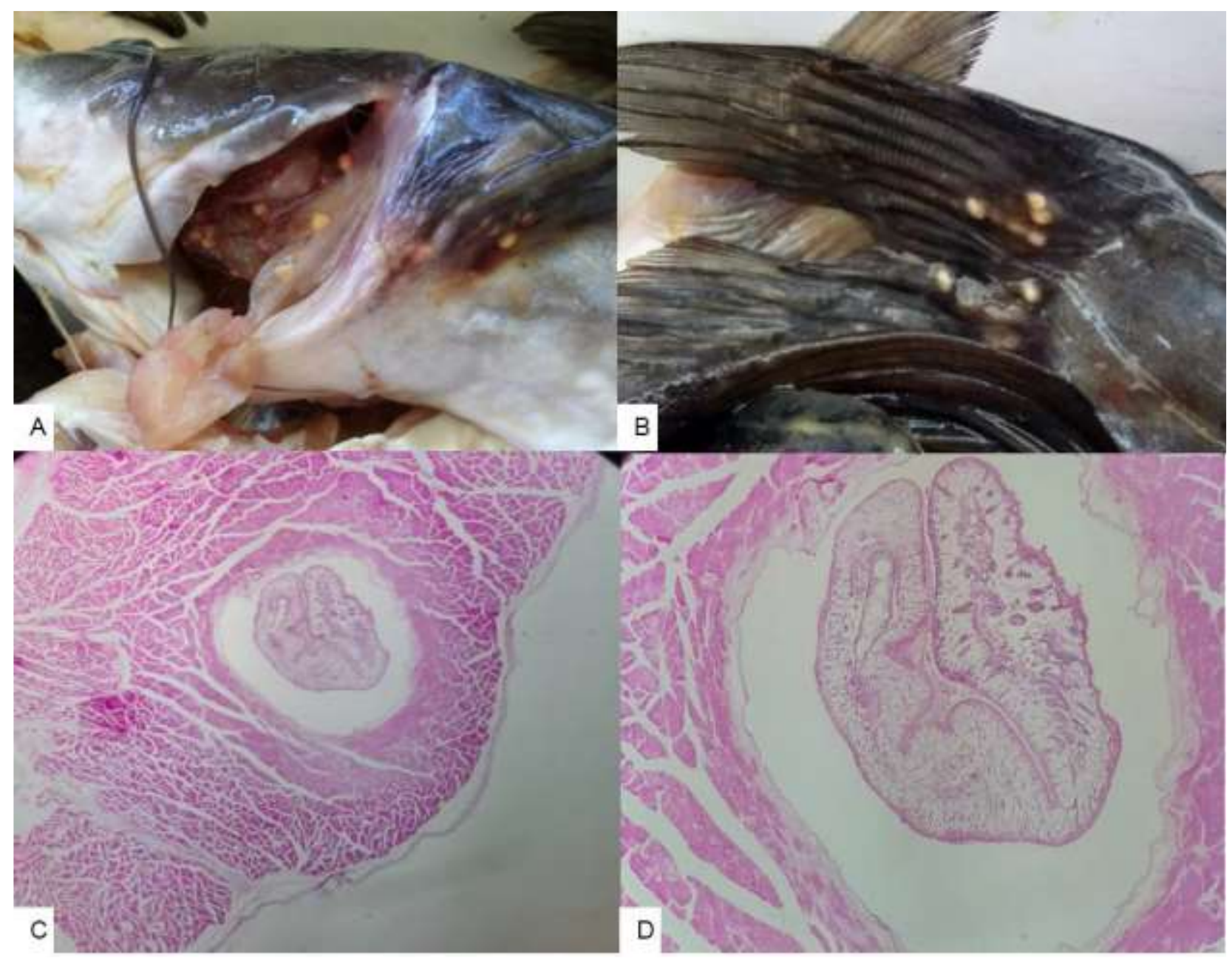

Fonte: Autores.

A escolha dos primers de regiões específicas foi realizada utilizando a ferramenta "pick primers" disponível na plataforma, apesar disso, optou-se por desenhar três pares de primers (Tabela 2).

As amostras com extração de DNA confirmadas foram submetidas à PCR. Os componentes da reação foram Master Mix (Ludwig Biotec $®$ ), $45 \mu \mathrm{L}$ de mix, $1 \mu \mathrm{L}$ de cada primer (F e R), $1 \mu \mathrm{L}$ de DNA de amostras (aproximadamente 100 mg de DNA) e $2 \mu \mathrm{L}$ de água livre de RNAses e DNAses. O volume da reação foi de $50 \mu \mathrm{L}$. 
Tabela 2. Primers utilizadas na PCR para detecção de Clinostomum spp.

\begin{tabular}{ccc}
\hline Nome & \multicolumn{1}{c}{ Sequências } & Amplicon \\
\hline \multirow{2}{*}{ Clin 1 } & F 5' AGCCTACCCGTATCTGTTGC & 460 pb \\
& R 5' GTGATCCACCG0CTCAGAGTT & \\
\hline \multirow{2}{*}{ Clin 2 } & F 5' TTTTGCCAGGAGCGACAGAA & $345 \mathrm{pb}$ \\
& R 5' TCTTCATCGACACACGAGCC & \\
\hline \multirow{2}{*}{ Clin 3 } & F 5' TGAAGAGTGCAGCCAACTGT & $360 \mathrm{pb}$ \\
& R 5' CTCATTAAGCCACGACCCGA & \\
\hline
\end{tabular}

Fonte: Autores.

As condições utilizadas no termociclador foram: Hold de $95^{\circ} \mathrm{C}$ por 2 minutos; PCR em 3 etapas $\left(95^{\circ} \mathrm{C}\right.$ por 30 segundos, $48^{\circ} \mathrm{C}$ por 1 minuto, $72^{\circ} \mathrm{C}$ por 1 minuto e 15 segundos) com 40 ciclos de repetições; Hold final a $4^{\circ} \mathrm{C}$ por 1 minuto e finalização da reação. Em seguida, após a padronização com amostras positivas, utilizamos o mesmo padrão para avaliar amostras capturadas diretamente pela técnica molecular.

\section{Resultados e Discussão}

Dentre as 174 amostras de jundiá recebidas, a prevalência de parasitismo por Clinostomum spp. com diagnóstico através de chaves parasitológicas foi de 36,21\%, com variações da prevalência de acordo com os pontos relatados de captura dos espécimes de Jundiá (Tabela 3).

A partir da PCR padronizada, realizou-se a técnica em todas as 174 amostras de Rhamdia quelen recebidas, das quais $63(36,21 \%)$ testaram positivo para Clinostomum spp. Os resultados obtidos confirmaram a prevalência obtida através dos métodos tradicionais, assemelhando-se aos trabalhos descritos na região em que as prevalências de parasitismo foram próximas de 40\% (Vianna et al., 2005; Dias et al., 2016).

Em relação as reações (PCR) também foram positivas tanto para as amostras histologicamente confirmadas quanto para amostras submetidas ao teste sem diagnóstico prévio. Apesar disso, nas condições de corrida empregadas, não houve reações positivas utilizando o primer Clin2. Somente as reações utilizando os primers Clin1 e Clin3 foram capazes de detectar e amplificar fragmentos de DNA de Clinostomum spp. extraídos de lesões em tecidos musculares de Jundiás.

Tabela 3. Número de espécimes de Jundiá (Rhamdia quelen) parasitados por Clinostomum spp. sobre o total de amostras analisadas e a prevalência do parasitismo em diferentes pontos de captura.

\begin{tabular}{ll}
\hline Ponto de captura & Positivos/Total - (Prevalência) \\
\hline Ponto 1 - Lagoa do Fragata & $6 / 17-(35,29 \%)$ \\
Ponto 2 - Barragem Eclusa & $3 / 23-(13,04 \%)$ \\
Ponto 3 - Foz do Piratini & $10 / 29-(34,48 \%)$ \\
Ponto 4 - Lagoa Formosa & $19 / 32-(59,37 \%)$ \\
Ponto 5 - Santa Isabel & $25 / 73-(34,25 \%)$ \\
\hline Total & $63 / 174-(36,21 \%)$ \\
\hline
\end{tabular}

Fonte: Autores.

Os produtos da PCR realizadas utilizando os primers Clin1 e Clin3 apresentaram bandas nas posições e tamanhos esperados, 460 pares de bases (Clin1) e 360 pares de bases (Clin3) (Figura 2). Desse modo, a PCR padronizada neste estudo 
demonstra-se efetiva na deteç̧ão de Clinostomum spp. a partir de lesões musculares em $R$. quelen, podendo ser aplicada no intuito de auxiliar o diagnóstico histopatológico desse parasita.

Considerando o potencial zoonótico desse parasita, a eficácia no diagnóstico desse parasita em Jundiás torna-se relevante, uma vez que já existem relatos de casos de infecções humanas por C. complanatum (Park et al., 2009; Lee et al., 2017) em países asiáticos e, com a ampla disseminação da culinária oriental, inclusive no Brasil, pode-se tornar um fator de risco para consumidores desses alimentos (Williams et al., 2020).

As traíras (Hoplias malabaricus), espécie abundante na região e de maior importância econômica, como também algumas outras espécies, têm relatos de parasitismo por Clinostomum spp (Costa; et al., 2015). Porém a sua prevalência parece ser menor ou menos relatada nos demais estudos, e o uso desta ferramenta irá ajudar a melhorar o diagnóstico dessa doença em várias espécies de hospedeiros.

Figura 2. Revelação da PCR para detecção e amplificação de fragmentos de DNA de Clinostomum spp. em amostras de músculo de Jundiás (Rhamdia quelen) por Eletroforese de DNA em gel de agarose 1\%. Slot1: Ladder 100pb; Slot2: PCR (Primer Clin1 com controle positivo); Slot3: PCR (Primer CLin1 com amostra de campo); Slot4: Ladder 100 pb; Slot5: PCR (Primer Clin2 com controle positivo); Slot6: PCR (Primer Clin2 com amostra de campo); Slot7: PCR (Primer Clin3 com controle positivo); Slot8: PCR (Primer Clin 3 com amostra de campo).

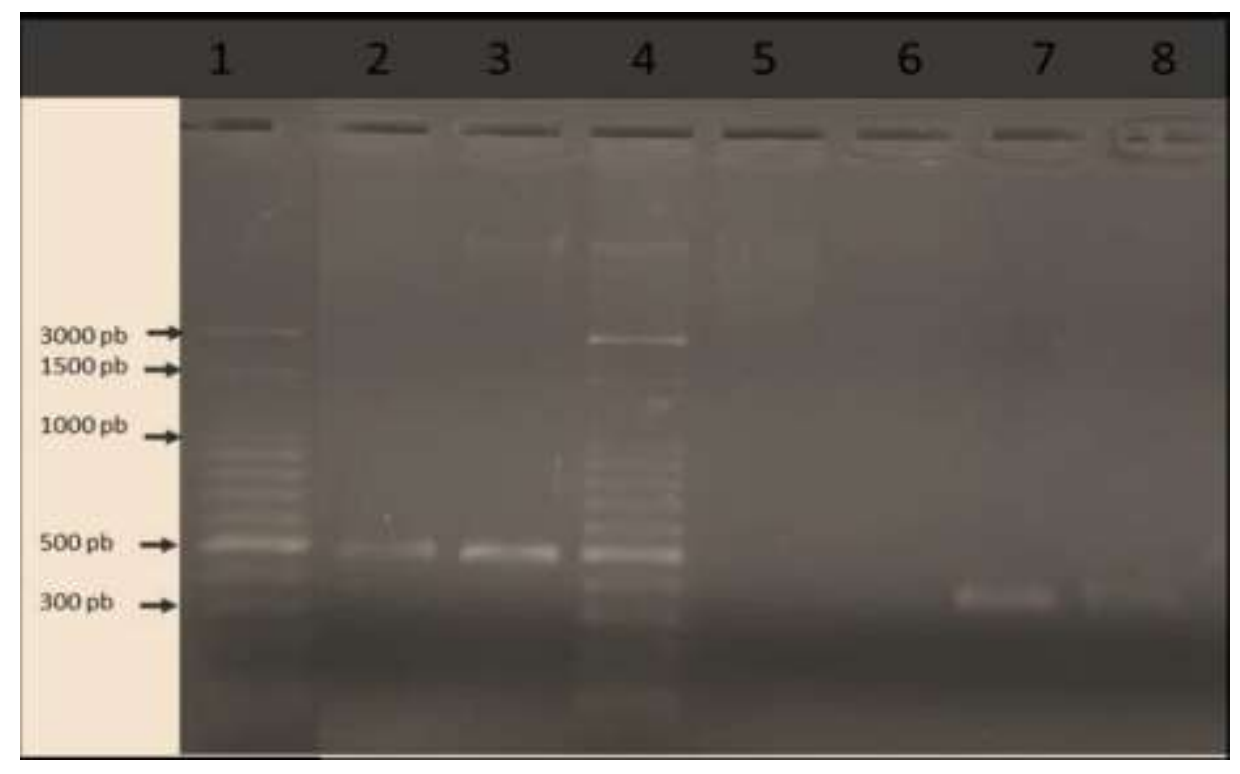

Fonte: Autores.

A detecção deste parasito por PCR irá auxiliar inclusive na busca por DNA de ovos de Clinostomum nas fezes de pássaros hospedeiros, ajudando assim a realizar estudos epidemiológicos mais completos e complexos e gerando dados mais robustos que irão auxiliar os pesquisadores a adotar futuras medidas de controle para minimizar os riscos de contaminação dos peixes destinados ao consumo humano. Garantindo assim a segurança alimentar nesta cadeia, atingindo todos os níveis dela, desde a pesca artesanal, piscicultura e a indústria de pescados.

Adicionalmente, o diagnóstico eficaz também auxilia em estudos epidemiológicos, possibilitando melhores avaliações sobre a prevalência e incidência de casos de Clinostomum em Jundiás, uma espécie predominante desde o sudeste do México até o centro da Argentina (Dias et al., 2016). 


\section{Considerações Finais}

De acordo com os resultados, a prevalência de infecções por Clinostomum na amostra estudada, a partir de animais da região estuária da Laguna dos Patos e Canal São Gonçalo é de 36,21\%. Além disso, PCR apresenta-se como uma ferramenta eficaz na detecção de Clinostomum a partir de lesões de tecidos provenientes de Rhamdia quelen, pois a técnica foi capaz de confirmar diagnósticos positivos previamente confirmados e detectar novos positivos em amostras sem prévia avaliação histopatológica.

Trabalhos futuros utilizando a PCR padronizada neste estudo, consolidarão a técnica como uma ferramenta auxiliar no diagnóstico desse parasita elevando não só a sensibilidade, mas também a rapidez do teste. Tais fatores serão de grande importância para futuros estudos epidemiológicos, assim como para saúde pública, visto que o consumo de peixes de água doce, típico da culinária oriental, encontra-se em expansão no Rio Grande do Sul e no Brasil.

\section{Agradecimentos}

Os autores gostariam de agradecer a Coordenação de Aperfeiçoamento de Pessoal de Nível Superior - Brasil (CAPES), Conselho Nacional de Desenvolvimento Científico e Tecnológico (CNPq), e Fundação de Amparo à Pesquisa do Estado do Rio Grande do Sul (FAPERGS).

\section{Referências}

Costa, D. P. C., Monteiro, C. M. \& Brasil-Sato, M. C. (2015). Digenea of Hoplias intermedius and Hoplias malabaricus (Actinopergygii, Erythrinide) from upper São Francisco River, Brazil. Brazilian Journal of Veterinary Parasitology, 2961, 129-135.

Dias, M. L. G. G., Minte-Vera, C. V., Eiras, J. C., Machado, M. H., Souza, G. T. R. \& Pavanelli, G. C. (2006). Ecology of Clinostomum complanatum Rudolphi, 1814 (Trematoda: Clinostomidae) infecting fish from the floodplain of the high Paraná River, Brazil. Parasitology research, $99,675-681$.

Dias, J. S., Pozza, A., Pesenti, T. C., Pereira Jr, J. \& Berne, M. E. A. (2016). Helmintos parasitos de Rhamdia quelen (Quoy \& Gaimard, 1824) no sul do Brasil. Science and Animal Health, 4, 2-20.

Eiras, J. C., Dias, M. L. G., Pavanelli, G. C. \& Machado, M. H. (1999). Histological Studies on the Effects of Clinostomum marginatum (Digenea: Clinostomidae) in its Second Intermediate Host Loricariichthys platymetopon (Osteichthyes, Loricariidae) of the Upper Paraná, Brazil. Acta Scientifica, 21, $237-241$.

Hara, H., Miyauchi, Y., Tahara, S. \& Yamashita, H. (2014). Human laryngitis caused by Clinostomum complanatum. Nagoya journal of medical science, 76, 181.

Lee, G. S., Park, S. W., Kim, J., Seo, K. S., You, K. W., Chung, J. H., Moon, H. C. \& Hong, G. Y. (2017). A case of endoscopically treated laryngopharyngitis resulting from Clinostomum complanatum infection. Korean Journal of Gastroenterology, 69,177-180.

Lo, C. F., Huber, F., Kou, G. H. \& Lo, C. J. (1981). Studies of Clinostomum complanatum (RUD., 1819). Fish Pathology, 15, $219-227$.

Miller, D. L., Bursey, C. R., Gray, M. J. \& Smith, L. M. (2004). Metacercariae of Clinostomum attenuatum in Ambystoma tigrinum mavortium, Bufo cognatus and Spea multiplicata from West Texas. Journal of Helminthology, 78, 373-376.

Park, C. W., Kim, J. S., Joo, H. S. \& Kim, J. (2009). A human case of Clinostomum complanatum infection in Korea. The Korean journal of parasitology, 47, 401.

Pavanelli, G. C., Eiras, J. C. \& Takemoto, R. M. (1998). Doenças de peixes: Profilaxia. Diagnóstico e Tratamento, 3.

Pereira, A. S., Shitsuka, D. M., Parreira, F. J., \& Shitsuka, R. (2018). Metodologia da pesquisa científica. UFSM. https://repositorio.ufsm.br/bitstream/handle/ 1/15824/Lic_Computacao_Metodologia-Pesquisa-Cientifica.pdf?sequence=1.

Silva, A. S., Monteiro, S. G., Doyle, R. L., Pedron, F. A., Filipetto, J. E. \& Radunz-Neto, J. (2008). Ocorrência de Clinostomum complanatum em diferentes espécies de peixes de uma piscicultura do Município de Santa Maria-RS. Veterinária e Zootecnia, 15, 27-32.

Simsek, E. (2018). Occurrence and molecular characterization of Clinostomum complanatum (Trematoda: Clinostomidae) in freshwater fishes caught from Turkey. Parasitology Research, 117, 2117-2124.

Song, H. B., Choi, M. H. \& Chung, E. J. (2018). Human laryngeal infection by Clinostomum complanatum. The American journal of tropical medicine and hygiene, 98, 7 .

Thatcher, V. E. (1981). Patologia de peixes da Amazônia Brasileira, 1. Aspectos gerais. Acta Amazonica, 11, $125-140$. 
Research, Society and Development, v. 10, n. 12, e509101220923, 2021

(CC BY 4.0) | ISSN 2525-3409 | DOI: http://dx.doi.org/10.33448/rsd-v10i12.20923

Vianna, R. T., Pereira Júnior, J. \& Brandão, D. A. (2005). Clinostomum complanatum (Digenea, Clinostomidae) density in Rhamdia quelen (Siluriformes, Pimelodidae) from South Brazil. Brazilian Archives of biology and Technology, 48, 635-642.

Williams, M., Hernandez-Jover, M. \& Shamsi, S. (2020). Fish substitutions which may increase human health risks from zoonotic seafood borne parasites: A review. Food Control, 107429. 